\title{
A prática de uma professora de Matemática ao conduzir uma discussão coletiva sobre sequências
}

\author{
Cátia Rodrigues \\ Instituto de Educação da Universidade de Lisboa \\ catiamat@gmail.com

\section{Luís Menezes} \\ Escola Superior de Educação do Instituto Politécnico de Viseu \\ menezes@esev.ipv.pt
}

\section{João Pedro da Ponte}

Instituto de Educação da Universidade de Lisboa

jpponte@ie.ulisboa.pt

\section{Resumo}

A aprendizagem da Matemática com compreensão pode ser incrementada pela participação dos alunos em discussões coletivas, em que estes são chamados a apresentar, justificar e argumentar as suas estratégias e as estratégias dos colegas e, posteriormente, a sistematizar as principais ideias emergentes nessa discussão. Este estudo, qualitativo e interpretativo, é um estudo de caso de uma professora de Matemática do $7^{\circ}$ ano de escolaridade, visa compreender a sua prática de condução de discussões coletivas, em interligação com o seu conhecimento didático, quando explora uma tarefa envolvendo sequências. Os resultados mostram que a professora, apoiada no seu conhecimento didático e na preparação da aula, organiza a discussão coletiva em três momentos (apresentação; comparação, avaliação e filtragem; e conclusão) nos quais empreende diversas ações de ensino.

Palavras-chave: Professor de Matemática. Prática de discussão. Conhecimento didático. Álgebra. Tarefas.

\section{The practice of a mathematics teacher in conducting the whole-class discussion on sequences}

\begin{abstract}
Mathematics learning with understanding can be improved by engaging students in whole-class discussions as they are called upon to present, justify and argue their strategies and the strategies of their colleagues and, later, to systematize the main ideas emerging from this discussion. This qualitative and interpretive study, is a case study of a grade 7 mathematics teacher, and aims to understand this practice in conducting the whole-class discussions, in connection with her didactic knowledge, when exploring a task involving sequences. The results show that the teacher, based on
\end{abstract}


her didactic knowledge and preparation of the lesson, organizes the whole-class discussion in three moments (presentation; comparison, evaluation and filtering; and conclusion) in which she undertakes various teaching actions.

Keywords: Mathematics teacher. Discussion Practice. Didactic Knowledge. Algebra. Tasks.

\section{Introdução}

A aprendizagem da Matemática com compreensão é potencializada pelo envolvimento dos alunos em discussões coletivas, em que são chamados a apresentar e justificar os raciocínios desenvolvidos durante o seu trabalho autónomo numa tarefa, argumentando sobre os raciocínios dos colegas, negociando significados e sistematizando conceitos (PONTE; QUARESMA, 2016; SHERIN, 2002; STEIN, ENGLE, SMITH; HUGHES, 2008). Para envolver os alunos numa discussão coletiva, o professor assume um papel importante, sustentado pelo seu conhecimento didático (PONTE, 2012) e pela sua preparação prévia da discussão (STEIN et al., 2008). Conduzir uma discussão coletiva constitui uma prática complexa, em que o professor precisa de ser capaz de empreender um conjunto de ações de ensino (PONTE; QUARESMA, 2016) que favoreçam o envolvimento dos alunos na discussão, apresentando com clareza as suas resoluções, confrontando estratégias, oferecendo justificações, colocando questões e sintetizando conceitos. Quando os alunos se envolvem em discussões a partir de tarefas algébricas, espera-se que a discussão contribua para o desenvolvimento de capacidades como a generalização e a simbolização, marcantes do trabalho em Matemática. Neste artigo, procuramos compreender a prática de condução da discussão coletiva de uma professora de Matemática do ensino básico (EB) português (7. a 9..$^{\circ}$ ano), em interligação com o seu conhecimento didático, quando explora uma tarefa envolvendo sequências.

\section{Práticas de condução da discussão coletiva e conhecimento didático}

A condução de discussões coletivas produtivas coloca desafios ao professor, já que a forma como organiza e promove a discussão influencia a participação dos alunos. Para isso, o professor pode apoiar-se em modelos como o das cinco práticas de Stein et al. (2008) - antecipar, monitorizar, selecionar, sequenciar e estabelecer conexões entre as respostas dos alunos - que decorrem sequencialmente em momentos distintos da preparação e da discussão. A primeira prática consiste na planificação da discussão, em que o professor pensa em possíveis estratégias que os alunos podem apresentar, nas dificuldades que podem enfrentar e como as ultrapassar, nas formas de 
organizar as intervenções dos alunos face às estratégias antecipadas, e nas representações a introduzir e conceitos a sistematizar. As práticas seguintes acontecem em sala de aula, quando o professor acompanha o trabalho dos alunos, identificando as estratégias que usam, as representações e conceitos que mobilizam, as dificuldades que enfrentam, os erros que cometem e as ideias importantes que merecem ser analisadas. $\mathrm{Na}$ prática seguinte, o professor, apoiado no acompanhamento feito aos alunos, seleciona as estratégias que merecem ser apresentadas e analisadas em coletivo. De seguida, pensa na sequência para as intervenções dos alunos, face às estratégias selecionadas. Por fim, dá início à discussão convidando os alunos a apresentarem, justificarem e argumentarem sobre os raciocínios desenvolvidos e expostos.

Iniciada a discussão, como indica Sherin (2002), o professor pode definir várias sequências de atividade com objetivos distintos: apresentação de ideias; comparação e avaliação; e filtragem. $\mathrm{Na}$ primeira, o professor convida os alunos a apresentar as suas estratégias, justificando os raciocínios desenvolvidos; na segunda, envolve os alunos na análise desses raciocínios procurando que os comparem e avaliem, de acordo com o que desenvolveram nas suas resoluções. Por último, desafia os alunos a centrarem a sua atenção em certos raciocínios, com vista à sua clarificação, aprofundamento ou generalização. $\mathrm{O}$ envolvimento dos alunos numa discussão favorece o desenvolvimento da sua capacidade de comunicação, nas vertentes de interpretação, justificação, explicação e argumentação. Esta forma de organizar a discussão promove um discurso que, inicialmente, é sujeito a um processo de afunilamento seguido de ampliação (SHERIN, 2002), já que se inicia com o professor a solicitar aos alunos as suas estratégias para, de seguida, selecionar algumas de modo a focar a sua atenção na análise de certos raciocínios que permitem a introdução de novas ideias na discussão, resultantes da clarificação, justificação ou ampliação dessa ideia específica.

O envolvimento dos alunos na discussão está relacionado com as ações empreendidas pelo professor durante a condução da discussão. Para Cengiz, Kline e Grant (2011), essas ações são de três tipos: ações de elicitar, com o objetivo de levar os alunos a apresentar as suas resoluções; ações de apoiar, que visam envolver o aluno na discussão, através do recordar o objetivo da discussão e da tarefa, sugerir a interpretação de um raciocínio, repetir um argumento, reforçar o seu pensamento e introduzir diferentes representações e contextos; e ações de ampliar, que supõem levar os alunos a apresentar e avaliar um argumento ou observação, oferecer um raciocínio para um argumento, comparar diferentes estratégias e usar a mesma estratégia em novos problemas.

Procurando clarificar a natureza destas ações, Ponte e Quaresma (2016) apresentam um modelo que inclui ações de convidar, apoiar/guiar, informar/sugerir e desafiar. As ações de convidar assumem a mesma natureza das ações de elicitar do modelo anterior. As ações de 
apoiar/guiar visam encaminhar os alunos na resolução da tarefa, através de questões ou observações do professor. As ações de informar/sugerir permitem ao professor introduzir informação, dar sugestões, apresentar argumentos ou validar respostas; e as ações de desafiar visam levar os alunos a produzir novas representações, interpretar ideias, formular conjeturas ou avaliar argumentos.

Estes modelos são semelhantes no propósito global das ações que o professor empreende para envolver os alunos na discussão. A primeira ação tem em vista iniciar a discussão, tornando públicas as estratégias desenvolvidas pelos alunos e as restantes ações pretendem dar continuidade à discussão com a finalidade de levar os alunos a apresentar e ampliar os seus raciocínios e a desenvolver uma melhor compreensão do conteúdo em estudo.

A realização destas ações está relacionada com o conhecimento didático do professor. Ponte (2012) encara este conhecimento numa perspetiva holística, integrando diversas vertentes (Figura 1). No centro deste modelo está o conhecimento da prática letiva (relacionado com aspetos da gestão curricular, como a escolha das tarefas, modo de trabalho na resolução das tarefas, modo de conduzir a comunicação matemática) que influencia e é influenciado pelos restantes, como o conhecimento da Matemática, que supõe o domínio de conceitos, procedimentos, representações e conexões; o conhecimento do currículo, relativo aos documentos que orientam o trabalho do professor, já que lhe permite estruturar o ensino e justificar opções tomadas; e o conhecimento dos alunos e da aprendizagem, que o ajuda a estruturar o ensino para garantir uma boa aprendizagem. Nas suas práticas de discussão coletiva, os professores mobilizam, constroem e reconstroem o seu conhecimento didático para ensinar, com particular relevo para o conhecimento da prática letiva. Esta visão do conhecimento do professor é inspirada nos trabalhos de Shulman (1986; 1987) e de Ball, Thames e Phelps (2008) e evita o problema da fragmentação e da falta de dinâmica entre os diversos domínios do conhecimento existente no modelo de Ball, Thames e Phelps (2008), ao não apresentar o conhecimento organizado em categorias.

Figura 1 - Vertentes do conhecimento didático do professor

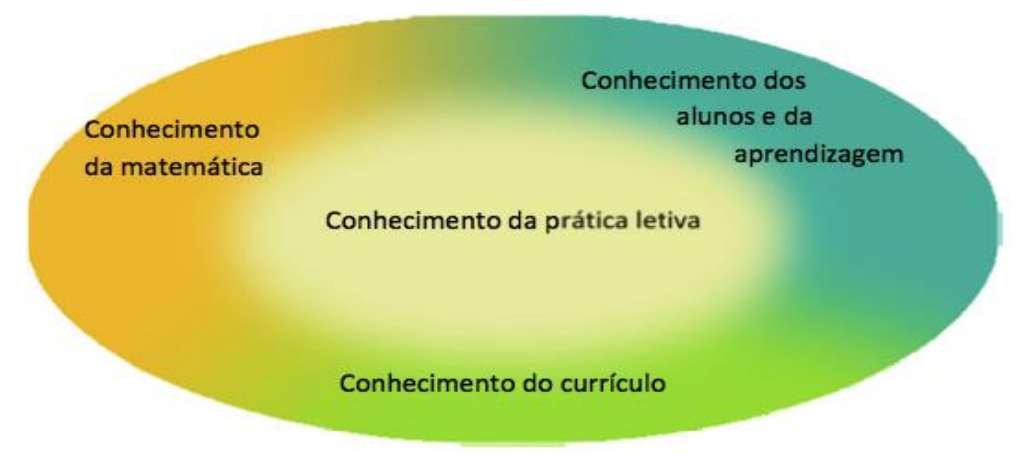

Fonte: Adaptado de Ponte (2012, p. 87). 


\section{Metodologia}

Este estudo, um recorte de um estudo mais alargado, é qualitativo e interpretativo (BOGDAN; BIKLEN, 1994), ao procurar compreender a prática de conduzir discussões coletivas de professores de Matemática a lecionar Álgebra no final do EB. Com este propósito, optou-se pelo design de estudo de caso. A parte empírica do estudo decorreu, durante o ano letivo de 2013-2014, com um grupo de professores de uma escola do centro de Portugal, que integraram o Projeto Práticas de discussão matemática no ensino da Álgebra (PPDMEA), sendo um deles (Ana) o caso de estudo aqui focado.

A investigadora do estudo (primeira autora deste artigo) dinamizou o PPDMEA em dez sessões de trabalho presencial (com três horas cada e espaçadas três a quatro semanas), com vista a desenvolver práticas de discussão matemática. O calendário das sessões foi acordado com os professores na primeira sessão de trabalho presencial e ajustado de acordo com a evolução do trabalho e as tarefas escolares dos professores. O projeto surgiu como uma ação de formação contínua, a pedido dos próprios professores. O trabalho realizado nas sessões incidiu, globalmente, sobre a reflexão de artigos e episódios de sala de aula relacionados com as discussões matemáticas e com o tema da Álgebra, a partir das experiências dos professores e a preparação de momentos de discussão para tarefas por eles escolhidas, baseado no modelo das cinco práticas de Stein et al. (2008). A tarefa matemática que aqui se expõe foi apresentada pela investigadora numa das sessões do projeto e escolhida pela professora para desenvolver em sala de aula com os alunos, aquando da abordagem do tema das Sequências. A investigadora não interagiu com os alunos durante a resolução da tarefa e da discussão coletiva.

A professora Ana tem 22 anos de serviço, no momento em que participa neste trabalho de investigação. Gosta de enfrentar novos desafios e, por isso, decide participar neste projeto. Sublinha que, com esse envolvimento, procura novas respostas para o que considera ser o formalismo da linguagem que caracteriza o trabalho em Álgebra: “Eu acho que é outra vez para ver (...) se pode ensinar isto de outra maneira, pronto, ou até se o que me está a preocupar é um bocado o formalismo" (EI set 2013). Deixa transparecer a sua preocupação com a sua prática letiva, ao reconhecer que a sua atuação na sala de aula tem repercussões na aprendizagem dos alunos.

A recolha de dados apoiou-se em dois processos principais: a observação de uma aula de Ana, gravada em áudio, com vista a estudar a sua atuação na condução da discussão; e a entrevista semiestruturada (EI), realizada no início do estudo, com o objetivo de dar voz à professora, permitindo conhecê-la melhor. A análise de dados recorre à análise de conteúdo e definição de categorias de codificação, tendo início com a recolha de dados, através da transcrição da entrevista 
e da gravação da aula observada (sempre que na transcrição da aula não é possível identificar o aluno que fala, usamos o termo Aluno). Os dados foram analisados, à luz dos modelos teóricos indicados, com vista à identificação de regularidades que originaram a formulação de diversas categorias (BARDIN, 1994). De seguida, fez-se uma primeira organização dos dados recolhidos nessas categorias, de modo a verificar a sua viabilidade e a proceder a ajustamentos, que culminaram no abandono de algumas categorias e na definição de outras, por um processo recursivo, até se alcançar as categorias indicadas no Quadro 1, para a dimensão condução da discussão coletiva, apoiada por outras duas dimensões, conhecimento didático e preparação da discussão.

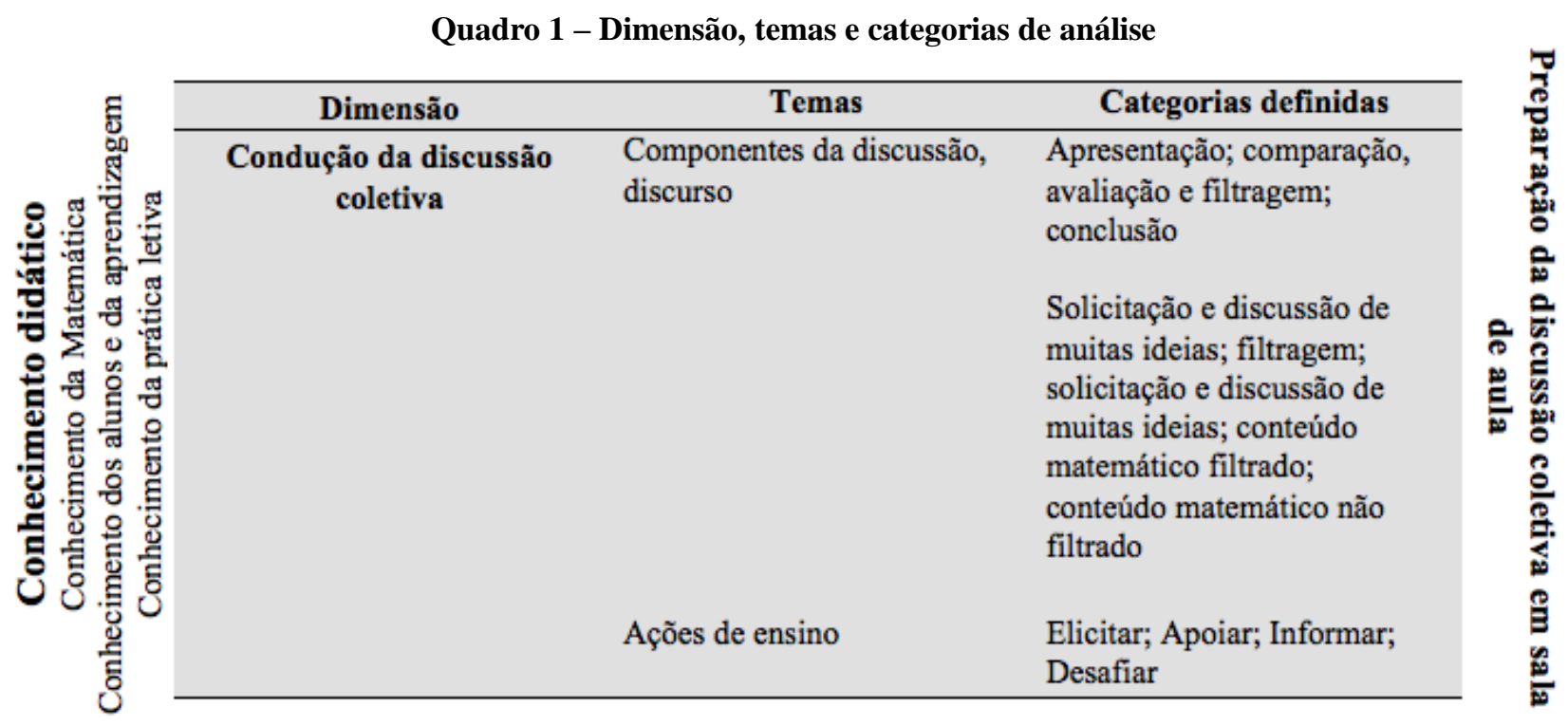

Fonte: Autores do estudo, 2014.

Neste artigo, as categorias usadas para as ações empreendidas pela professora na condução da discussão foram reconstruídas a partir do quadro teórico de Ponte e Quaresma (2016), face à análise preliminar de dados. Especificamente, usamos as categorias ações de elicitar para levar os alunos a apresentarem as suas estratégias; apoiar, para o ajudar a progredir na sua apresentação, explicação e justificação; informar, para reforçar alguma ideia especial, alertar para algum raciocínio e fazer sínteses; e desafiar, para levar o aluno a aprofundar e/ou ampliar o seu raciocínio, através do pedido de justificações, explicações, introdução de representações e questionamento aos colegas. As categorias usadas no tema componentes da discussão também foram reajustadas do modelo de Sherin (2002), agrupando-se as duas últimas componentes numa só e incluindo uma terceira designada, neste estudo, de conclusão, por traduzirem melhor a forma como a professora conduziu a discussão em sala de aula. O conhecimento didático da professora foi analisado segundo o modelo de Ponte (2012), por valorizar uma dimensão integradora das diversas vertentes do 
conhecimento: alunos e aprendizagem, prática letiva e Matemática.

\section{Apresentação das estratégias de resolução}

Após a apresentação da tarefa "Palitos" (Figura 2) e do trabalho autónomo dos alunos em pequenos grupos, Ana inicia uma terceira fase na aula - a discussão coletiva - comunicando à turma o objetivo que tem para a discussão - ação de elicitar: "Vamos lá tentar fazer um apanhado do que se passou aqui e queria que depois vocês ajudassem aqui a esclarecer algumas dúvidas que eu tenho" (Aula_Seq_nov 2013 - AS_11/13). Com esta ação pretende clarificar junto dos alunos o que é esperado da sua participação e envolvimento na discussão: apresentarem e explicarem as suas estratégias, com vista à clarificação de raciocínios e desenvolvimento de uma compreensão mais aprofundada do que está a ser analisado.

Figura 2 - Tarefa Palitos

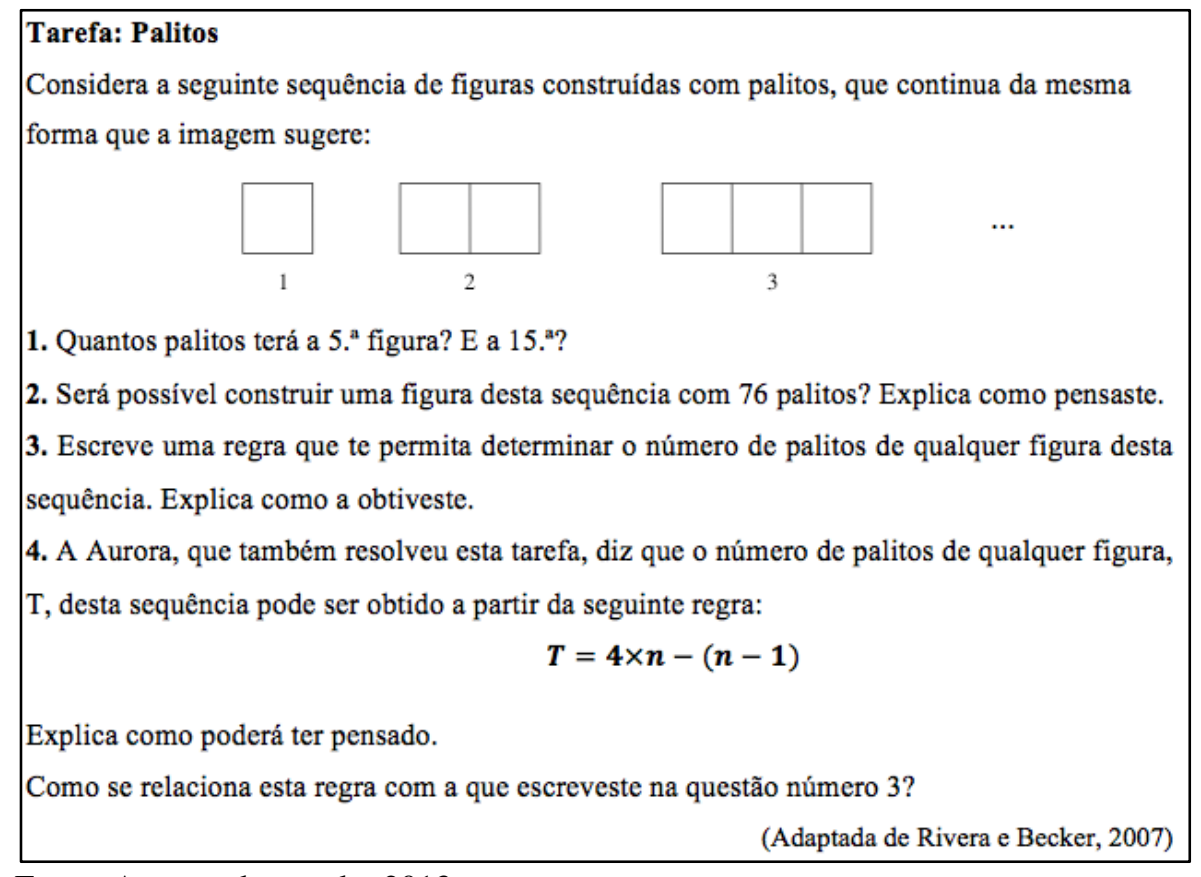

Fonte: Autores do estudo, 2013.

A primeira questão da tarefa envolve somente a representação de dois termos próximos da sequência. Por isso, Ana decide iniciar a apresentação das estratégias pela segunda questão. Esta decisão é suportada pela informação que presta à turma, apoiada na preparação que faz da discussão em sala de aula, quando acompanhou o trabalho autónomo dos grupos de alunos: "a primeira questão não levantou dúvidas a nenhum grupo (...) toda a gente acertou" (AS_11/13) - ação de informar.

Ana dá início à apresentação das estratégias pela resolução mais frequente na turma. No entanto, antes de solicitar a partilha da primeira estratégia, recorre a uma ação de informar para 
comunicar o tipo de resoluções que emergiram durante o trabalho autónomo: "Na segunda questão, houve cinco grupos que fizeram uma continha, porque vocês, (...) tinham dito que já tinham pensado nas operações inversas quando estavam no $5 .^{\circ}$ ou $6 .^{\circ}$ ano. Por exemplo, tenho só aqui dois grupos que não fizeram, que fizeram de outra maneira" (AS_11/13). Deste modo, pretende despertar o interesse dos alunos para a análise de resoluções diferentes, comparando-as com a sua. Os alunos são alertados para outras estratégias que podem mobilizar em situações futuras, enriquecendo o seu conhecimento. Cumprido esse objetivo, decide incitar o primeiro grupo a apresentar a sua resolução - ação de elicitar - informando que pretende que seja exposta toda a estratégia: "Tudo que aí puseram, está bem?” (AS_11/13). Enquanto a aluna transcreve a sua resolução para o quadro, Ana resolve informar a turma de que a estratégia que está a ser exibida foi seguida por outros grupos: "Para além do grupo da Vera deve haver mais quatro grupos (...) a reconhecer aquela resolução, sim?” (AS_11/13) - ação de informar. Com esta ação, só possível pela preparação que faz da discussão em sala de aula, Ana visa captar a atenção dos alunos para a etapa seguinte: explicação da estratégia seguida, com vista a acrescentarem contributos ou completarem justificações.

Atendendo à particularidade dessa estratégia ter sido empregue por diversos grupos, Ana convida um aluno de outro grupo que também a empregou para explicar o raciocínio subjacente à resolução transcrita por Vera no quadro: "Alguém que tenha a resolução idêntica à da Vera quer explicar como é que... (...) vamos ouvir o que a Constança vai dizer.” (AS_11/13) - ação de elicitar. Com essa ação pretende levar os alunos a envolverem-se na apresentação de ideias. O desafio lançado é acolhido pelos alunos:

[L.1] Constança: Nós já sabíamos que a lei de formação era $3 n+1$ e então fizemos a operação inversa, fizemos $76-1$ a dividir por 3 .

Professora: Porque já tinham a lei de formação.

Constança: Sim.

[L.5] Prof : Então e quem não tem a lei de formação como é que resolveria? Não resolve? (AS_11/13)

Durante a apresentação da estratégia, Ana vai acompanhando o raciocínio repetindo ideias matemáticas importantes (L.3) - ação de apoiar. Com essa ação pretende clarificar o aspeto mais relevante da estratégia seguida. Contudo, sem deixar Constança concluir a sua intervenção, aproveita a oportunidade da ideia iniciada pela aluna para introduzir na apresentação mais algumas estratégias, com vista a aprofundar e levar os alunos a reconhecer que, para verificar a pertença de um termo à sequência, não é obrigatório começar por escrever o respetivo termo geral. Para tal, 
procura que os alunos analisem outras resoluções que emergiram na turma. Esta opção da professora ilustra como, numa discussão, é importante saber quando se deve parar para seguir uma ideia que revela ter potencial para aprofundar. O segmento de discussão seguinte mostra como o objetivo da professora é atingido ao fazer sobressair a análise de uma outra resolução - estratégia por tentativas.

\section{Comparação, avaliação e filttragem}

Ana, ao tomar a decisão de introduzir mais grupos na partilha de ideias, pretende levar os alunos a evoluírem nas suas ideias iniciais, comparando e avaliando raciocínios. Para tal, socorre-se de ações de desafiar, sob a forma de perguntas:

Profa $^{\mathrm{a}}$ : O que é que está aqui acontecer na resolução deste grupo? Ou do grupo da Eva?

Aluno: É o termo geral.

[L.10] Profa: É o termo geral outra vez. É uma concretização da Vera, já viram? (...) Perceberam o que aconteceu aqui? (...)

Aluno: Então e como é que eles descobriram que era logo o 25?

Prof ${ }^{\mathrm{a}}$ : Tens que perguntar ao grupo que fez isto.

Aluno: Fizemos por tentativas. (AS_11/13)

Ana promove a comparação de ideias, incitando os alunos a pensarem sobre uma ideia específica, resolver a mesma questão sem recurso à escrita do termo geral - filtragem - com vista a introduzir a resolução do grupo seguinte, já que envolve um raciocínio diferente e evidencia que os alunos que recorrem a estratégias menos formais também conseguem responder à questão colocada.

$\mathrm{Na}$ condução do discurso, Ana vai repetindo as ideias mais importantes das intervenções dos alunos (L.10), através de ações de apoiar. Recorre ainda a esta ação para questionar os alunos acerca da compreensão dos raciocínios comunicados. Essa prática leva a que os alunos a questionem (L.12), aproveitando essa oportunidade para os incentivar a colocarem as dúvidas aos colegas (L.13) - ação de desafiar. Essa opção mostra como encara o seu papel e o dos alunos na discussão e como pretende aproveitar as oportunidades que surgem para promover a aprendizagem dos alunos.

Ana dá continuidade à partilha de ideias introduzindo mais um grupo na discussão, com vista a alertar a turma para o rigor da linguagem matemática:

[L.15] Prof ${ }^{a}$ : O que me fez um bocadinho de espécie foi isto. (...) Então, 15 é igual a 46? 20 é igual a 61? E 25 é igual a 76? (...) Os meninos deste grupo têm agora oportunidade para se defenderem.

Viviane: A figura 15 era igual a 46 palitos, em 20 havia 61 e em 25 havia 76. 
Prof : Deixa-a falar. Então, na prática, o grupo da Eva provavelmente fez isto até [L.20] chegar a esta (impercetível) o que ela disse foi por tentativas. (...) Experimentaste com 15, estás a perceber? (...) Não estão a conseguir explicar nada do que estão a pensar, está bem? (impercetível) Com este aspeto claro que eu não quero. (...) Bastava ter dito a figura 15 tem não sei quantos palitos e se quisesse mostrar fazia esta conta. (AS_11/13)

A professora recorre a ações de informar para sinalizar a incorreção no registo. Desse modo, alerta os alunos para a necessidade de rigor da linguagem matemática, aspeto pouco valorizado pelos alunos na apresentação dos seus raciocínios. Salienta também a oportunidade que os alunos têm na clarificação dos raciocínios quando participam numa discussão coletiva (L.16-17) - ação de apoiar. Com a análise desta resolução, a professora pretende que estes erros não se repitam. Recorre ainda a esta ação para oferecer uma interpretação para o raciocínio da aluna, perante a dificuldade de ela se exprimir e avançar para além do que tem no seu registo. Aproveita também para realçar que a forma de apresentação da estratégia seguida não é válida, destacando como o devem fazer no futuro - referir a ordem e termo da figura.

Ana dá continuidade à discussão avançando para a questão 3 (Escreve uma regra que te permita determinar o número de palitos de qualquer figura desta sequência. Explica como a obtiveste) que solicita a escrita do termo geral da sequência. Opta por deixar vários alunos apresentarem a sua expressão para, finalmente, destacar o incumprimento do pedido no enunciado e a incorreção de um raciocínio seguido por vários grupos - justificar uma generalização com a verificação de casos particulares:

[L.25] Filipa: A regra para obter o número de palitos é $3 n+1$ (termo geral). Nós obtivemos vendo de figura para figura vai mais 3 palitos, mas no $1 .^{\circ}$ termo nós fazemos 3 vezes 1 mas não dá 4 então temos de somar mais 1 . (...)

Mara: A regra é $3 n+1$ porque em qualquer figura fazemos o número da ordem da figura vezes 3 mais 1 que dá o número de palitos certos. Figura 1, 3 vezes 1 é [L.30] igual a 3 mais 1 que dá 4. (...)

Eva: A sequência dá pulos de 3 em 3, logo é $3 n$. É $3 n$. Mas para dar é preciso por $3 n$ mais 1.

Prof ${ }^{\mathrm{a}}$ : E eu aqui quero chamar atenção, porque aqui diz: explica como obtiveste. E vocês não explicam, concretizam. (AS_11/13)

Ana opta por deixar vários alunos apresentarem a mesma expressão para o termo geral da sequência para mostrar que foi um raciocínio seguido por vários grupos e para destacar como interpretaram o pedido feito no enunciado - justificar a expressão do termo geral escrito. Para tal, recorre a ações de informar para clarificar que a justificação de um raciocínio pressupõe encontrar um caminho que seja válido para todos os termos da sequência e não a concretização para alguns 
termos e verificação da sua pertença à sequência. Contudo, não detalha mais esta questão porque é retomada a seguir:

[L.35] Prof : Eu gostava que nos preocupássemos agora aqui um bocadinho (...) Explica como poderá ter pensado e depois como se relaciona esta maneira com a anterior. Pronto e aqui na questão 4 foi uma desgraça, porque não houve qualquer tentativa da vossa parte. Há apenas o grupo da Vera que tenta. (AS_11/13)

Ana recorre à ação de informar para sublinhar a importância da análise da estratégia que se segue e que vem em linha com o segmento de discussão anterior - explicação de uma expressão do termo geral da sequência. Pretende promover o envolvimento dos alunos na discussão, já que apresentaram muitas dificuldades nas questões relacionadas com a justificação e interpretação de uma expressão do termo geral da sequência. Desta forma, a professora, apoiada numa ação de desafiar, convida os alunos a acompanhar um raciocínio para análise, com o objetivo de os ajudar a avançarem nas suas ideias iniciais:

Prof ${ }^{a}$ : Será que não conseguimos pensar na figura e ver o que é que aquelas coisas [L.40] têm a ver com os palitos, com os palitos que lá estão, com as figuras que lá estão? (...) Eu queria vos ajudar. Agora ninguém me pode tentar dizer a Aurora pensou 4 vezes $n$ menos abrir parêntesis $n$ menos 1 fechar parêntesis, pois não? (...) Ela pensou qualquer coisa que tinha a ver com as figuras que estavam em cima. (AS_11/13)

Perante a dificuldade dos alunos em explicar uma expressão do termo geral de uma dada sequência pictórica, detetada durante o acompanhamento do trabalho autónomo dos alunos, Ana decide negociar uma interpretação para o solicitado. Assim, opta por desafiá-los a relacionarem os conceitos de ordem e de termo da figura, com vista à compreensão da expressão para o termo geral da sequência - ação de desafiar. Clarifica, ainda, que uma justificação baseada somente na leitura em linguagem natural da expressão dada em linguagem matemática não é uma justificação válida ação de informar. Este alerta decorre do acompanhamento feito ao trabalho autónomo dos alunos, onde identifica que é o raciocínio seguido por alguns alunos. O raciocínio que oferece mostra-se pertinente, na medida em que desencadeia, por parte dos alunos, a apresentação de argumentos:

[L.45] Eva: Eu acho que é o número de palitos da figura. (...) E depois $n$ menos 1 é quando se acrescenta aquilo no meio.

Prof ${ }^{a}$ : O $n$ menos 1 é quando se acrescenta aquilo no meio? (...)

Clara: Nós quando juntamos os quadrados temos que tirar 1 do meio se não ficam lá dois. (...)

[L.50] Aluna: (impercetível) É o número da figura e o $n$ menos 1 é o número de palitos que se tira do meio.

Profa: Ah! (vários alunos falam ao mesmo tempo) O quê, o quê? (...)

Aluna: Ela multiplicou o número de lados de um quadrado.

Prof ${ }^{\mathrm{a}}$ : Pelo número da figura. E depois? 
[L.55] Aluna: Tirou os palitos que servem para unir os dois.

Prof ${ }^{a}:$ (...) O número de palitos que tiramos é sempre o quê? O número da figura menos um. Na figura 3 tira-se 2. Na figura 2 eu tiro 1. (AS_11/13)

Perante os contributos da aluna, Ana recorre à ação de apoiar para repetir o argumento apresentado, mas sob a forma de interrogação. Com essa opção, mostra aos alunos que estão a evoluir, contudo, é preciso completar ou clarificar esse argumento - filtragem das ideias partilhadas. A sua intenção é alcançada e as justificações começam a emergir, levando-a a recorrer a ações de apoiar para completar os contributos dos alunos e os ajudar a avançar com as suas explicações. A sua opção por ir selecionando os aspetos mais importantes introduzidos pelos alunos revela-se eficaz na medida em que eles conseguem fazer progressos na interpretação com compreensão da expressão dada. As suas ações de apoiar assumem também a forma de interrogação (L.52), com vista a levar os alunos a destacar um contributo importante que foi apresentado e que será útil para a compreensão do raciocínio em análise. Esse questionamento desencadeia também a introdução de mais argumentos na discussão, contribuindo para a sua evolução. Os alunos introduzem ideias novas que permitem completar o raciocínio iniciado. Isto acontece porque Ana transmite-lhes confiança, incentiva a continuidade dos raciocínios (L.54) e repete afirmações com recurso a linguagem matemática correta (L.54) - ações de apoiar. Depois de os alunos alcançarem o objetivo que definiu, interpretarem uma expressão para o termo geral da sequência dada, relacionando termo e ordem da figura, decide concretizar com alguns casos particulares para tornar o raciocínio mais claro para a turma, já que o trabalho com variáveis é sempre complexo para alunos deste ano de escolaridade.

\section{Conclusão da discussão}

Ana dá continuidade ao discurso desafiando os alunos a sintetizarem, por escrito, os contributos apresentados - ação de desafiar - como exibe o segmento seguinte:

Prof ${ }^{\mathrm{a}}$ : O que é que vamos escrever?

Aluna: Multiplicou o número de lados de um quadrado pelo número da figura e [L.60] tirou-se os palitos que estão sobrepostos.

Profa: Pronto, olhem não digo mais nada. (...) E neste caso se calhar podíamos deixar entre parêntesis que os palitos sobrepostos são sempre. (...) o número da figura menos 1, não é? Foi isso que dissemos. (AS_11/13)

Ao desafiar os alunos a registar as conclusões estabelecidas oralmente, Ana pretende levá-los a sistematizar as ideias que emergiram na discussão e a relacionarem-nas com a expressão do termo geral apresentado - conclusão. Recorre, ainda, a ações de apoiar para completar o 
raciocínio da aluna, com vista a destacar um aspeto importante da expressão apresentada e talvez a ideia mais forte: análise do padrão que configura a imagem e respetiva associação à ordem da figura. O contributo que introduz na conclusão formulada pelos alunos (L.61-63), permite-lhes melhorar a sua conclusão e desenvolver uma compreensão mais aprofundada do que estão a sistematizar, a partir das suas ideias iniciais. Durante esse processo, responsabiliza-os pelas conclusões que retiram e dá-lhes indicação de que estão a corresponder ao esperado (L.61) - ação de apoiar. Decide focar a conclusão no último aspeto discutido por ter sido o mais desafiante para os alunos e também porque é o que traduz a generalização de vários raciocínios desenvolvidos com o seu trabalho na tarefa.

Com a conclusão, os alunos voltam a sentir necessidade de concretizar para um termo específico da sequência, para atribuírem significado à expressão interpretada. Nesse sentido, questionam a professora sobre a verificação do termo de ordem quatro. Ana opta por não responder à questão, mas devolve-a à turma, auxiliando na construção dos raciocínios que permitem chegar à resposta:

Prof $f^{\text {a: }}$ O Daniel está a perguntar o que acontecia na figura 4. O que é que eu fazia [L.65] na figura 4 aqui?

Aluna: 4 menos 1.

Prof ${ }^{a}: 4$ menos 1 . Então vamos fazer as contas. 16 menos 3 que dá?

Aluna: Dá 13.

Prof $f^{\text {a: }}$ 13. Vamos fazer ali a figura 4.

[L.70] Aluna: 3 vezes 4 mais 1. (...)

Prof ${ }^{a}$ : É, é. Mas multiplicas primeiro o número da figura por 4. (AS_11/13)

Ana recorre a uma ação de desafiar para levar os alunos a esclarecerem uma dúvida de um colega. Perante os contributos dos alunos, socorre-se de uma ação de apoiar para repetir o argumento apresentado pela aluna e para indicar o raciocínio que devem realizar de seguida (L.67). Recorre, ainda, a esta ação para sugerir a determinação do mesmo termo da sequência usando a outra expressão generalizada, com vista a levar os alunos a concluírem que o quarto termo da

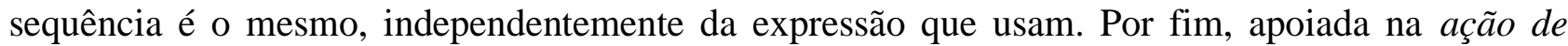
informar, alerta para a prioridade das operações (L.71) na resolução da expressão numérica [4n $(n-1)]$. Toda a sua ação contribui para o esclarecimento da dúvida do aluno.

Em suma, o discurso de Ana na condução desta discussão revela uma sequência de dois processos fundamentais: (i) solicitação e discussão de muitas ideias; e (ii) filtragem. Assim, inicia a discussão com o convite à partilha das estratégias de resolução da questão 2 da tarefa. Logo de seguida, filtra uma ideia da aluna relacionada com a verificação da pertença de um termo à 
sequência, para promover uma nova introdução de ideias relacionadas com a da aluna - ampliação. Essa ação permite introduzir novas estratégias na discussão, em consequência dessa filtragem. As novas estratégias apresentadas permitem-lhe filtrar novamente o discurso para alertar os alunos para a necessidade de rigor da linguagem matemática.

Avança para outra questão da tarefa que gera um discurso semelhante, isto é, tem início com a apresentação das estratégias seguidas por vários grupos, proporcionando-lhe focar a atenção dos alunos na incorreção do raciocínio seguido por esses grupos - filtragem. A discussão desse raciocínio permite a passagem para a questão seguinte da tarefa, através da solicitação da partilha das estratégias desenvolvidas. Perante a dificuldade dos alunos, Ana decide oferecer um raciocínio para eles analisarem - filtragem - que desencadeia a introdução de vários contributos na discussão - solicitação de muitas ideias. Esses contributos são depois sistematizados numa conclusão formulada pelos alunos.

$\mathrm{Na}$ condução da comunicação, Ana mostra diversas preocupações com os raciocínios partilhados, já que ao solicitar várias ideias para a discussão não tem controlo sobre os contributos que serão introduzidos - conteúdo matemático não filtrado - para, posteriormente, focar a atenção dos alunos nas ideias que reconhece que têm potencial para ser aprofundadas - conteúdo matemático filtrado - como foi o caso da discussão da verificação da pertença de um termo à sequência, desconhecendo a expressão do termo geral; a interpretação e explicação de uma expressão para o termo geral da sequência, diferente de outro escrito, e a explicação de generalizações estabelecidas.

A prática de conduzir discussões da professora é apoiada no seu conhecimento didático, em particular, socorre-se do seu conhecimento da Matemática para decidir as resoluções que pretende discutir em coletivo e para identificar e justificar os erros cometidos pelos alunos; do seu conhecimento dos alunos e da aprendizagem em articulação com o seu conhecimento da prática letiva para selecionar os alunos a apresentarem as suas estratégias e para solicitar aos colegas a explicação das estratégias expostas, para fomentar o esclarecimento de dúvidas junto dos colegas e não da professora e para promover a comunicação matemática, nas vertentes da interpretação, exposição, justificação e discussão.

\section{Discussão e conclusão}

A prática de condução da discussão coletiva de Ana mostra que, apoiada na preparação da discussão em sala de aula e no seu conhecimento didático, empreende um conjunto de ações de ensino 
diverso, de acordo com o momento da discussão em que se encontra e com os objetivos que tem para essa discussão e para a aprendizagem dos alunos (Quadro 2).

Quadro 2 - Ações de ensino de Ana na condução a discussão coletiva

\begin{tabular}{|c|c|c|}
\hline $\begin{array}{c}\text { Ações da } \\
\text { professora }\end{array}$ & Objetivos (levar o aluno a...) & Objetivos da professora \\
\hline ações de elicitar & $\begin{array}{l}\text { - Apresentar e explicar as suas } \\
\text { estratégias de resolução } \\
\text { - Conhecer o que é esperado da sua } \\
\text { intervenção }\end{array}$ & $\begin{array}{l}\text { - Tornar públicas as estratégias de resolução emergentes } \\
\text { - Envolver os alunos na discussão }\end{array}$ \\
\hline ações de apoiar & $\begin{array}{l}\text { - Argumentar sobre os seus raciocínios } \\
\text { - } \text { Melhorar os seus contributos e } \\
\text { - Focar aspetos importantes }\end{array}$ & $\begin{array}{l}\text { - Clarificar aspetos importantes das resoluções } \\
\text { apresentadas } \\
\text { - Alertar para o rigor da linguagem matemática na } \\
\text { comunicação de raciocínios } \\
\text { - Transmitir confiança aos alunos para avançarem } \\
\text { com os seus raciocínios, explicações, justificações }\end{array}$ \\
\hline $\begin{array}{l}\text { ações de } \\
\text { informar }\end{array}$ & $\begin{array}{l}\text { - } \text { Compreender ações tomadas pela } \\
\text { professora } \\
\text { - } \text { Conhecer resoluções diferentes } \\
\text { - Aumentar o leque de estratégias } \\
\text { - Analisar resoluções incorretas do } \\
\text { ponto de vista da utilização da } \\
\text { linguagem matemática } \\
\text { - Reconhecer que uma certa explicação } \\
\text { não é matematicamente válida }\end{array}$ & $\begin{array}{l}\text { - Envolver os alunos na discussão } \\
\text { - Comparar e analisar estratégias diversas }\end{array}$ \\
\hline $\begin{array}{l}\text { ações de } \\
\text { desafiar }\end{array}$ & $\begin{array}{l}\text { - Comparar estratégias diferentes } \\
\text { - } \text { Sistematizar informação } \\
\text { - Restionar os colegas } \\
\text { colegas }\end{array}$ & $\begin{array}{l}\text { - Introduzir estratégias diversificadas em análise } \\
\text { - Envolver os alunos na sistematização das principais } \\
\text { ideias discutidas }\end{array}$ \\
\hline
\end{tabular}

Fonte: Autores do estudo, 2018.

A professora organiza a discussão coletiva em três momentos principais: (i) apresentação; (ii) comparação, avaliação e filtragem; e (iii) conclusão e gere o discurso segundo um processo de ampliação seguido de estreitamento (Figura 3). Especificamente, Ana começa por solicitar um grupo de alunos para apresentar a sua estratégia de resolução - solicitação e discussão de muitas ideias - correspondendo ao momento de apresentação das estratégias de resolução. Seguidamente, foca a atenção dos alunos num aspeto particular - filtragem das ideias partilhadas - de modo a promover a comparação, avaliação e filtragem. A análise desse raciocínio específico tem como objetivo despertar o surgimento de mais ideias na discussão, através da inclusão de mais estratégias de resolução para comparação, originando, em termos de discurso, uma nova solicitação $e$ discussão de mais ideias. Esse encadeamento continua até à conclusão da discussão. 
Figura 3 - Conhecimento e prática de condução da discussão coletiva de Ana

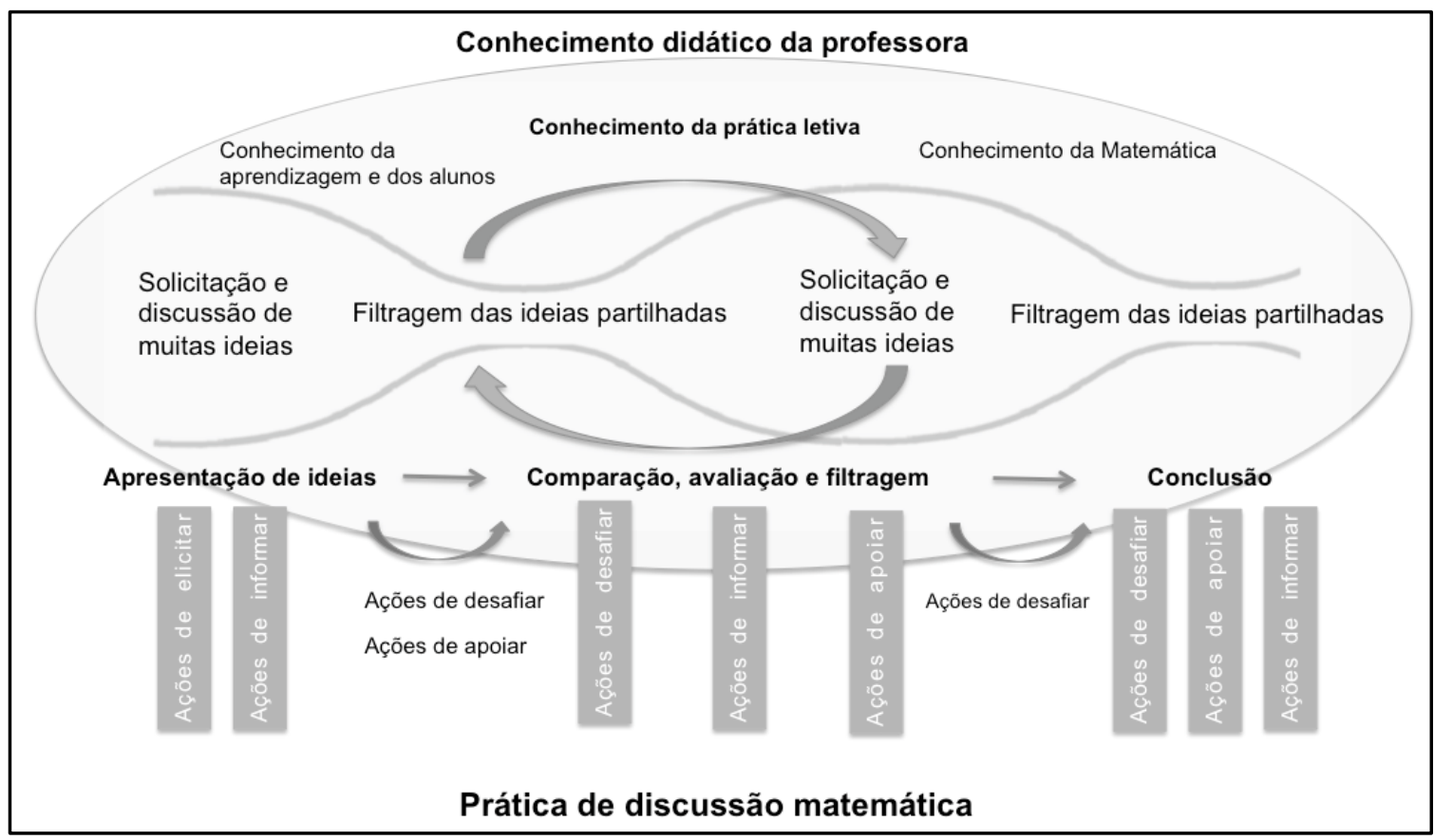

Fonte: Autores do estudo, 2018.

Para promover a apresentação de estratégias, Ana recorre, essencialmente, a ações de informar e de elicitar. A combinação deste tipo de ações permite aos alunos conhecer estratégias diferentes e compreender a sua justificação. Este aspeto é fundamental para que os alunos não encarem a discussão coletiva como um simples desfile de apresentações.

Promove a transição da apresentação para a comparação, avaliação e filtragem através da articulação entre as ações de apoiar e desafiar, levando os alunos a pensarem sobre uma outra abordagem, que permite contrariar ideias prévias relacionadas com a verificação da pertença de um termo a uma sequência. Conduz o segundo momento da discussão através da combinação de ações de apoiar, informar e desafiar, onde os alunos comparam e avaliam resoluções apresentadas, são alertados para a importância de comunicarem com rigor e clareza os seus raciocínios, completam contributos, questionam os colegas e argumentam sobre os seus raciocínios.

Neste estudo, a professora inicia a discussão com a análise de uma resolução correta e promove a comparação com vista à análise de outra resolução que precisa de ser clarificada em termos de uso da linguagem matemática, ao contrário do estudo de Ponte, Quaresma e Mata-Pereira (2017), que começa com a apreciação de uma resolução incorreta e introduz outras resoluções com o objetivo de fomentar a comparação de resoluções corretas e incorretas.

Durante a comparação e avaliação de estratégias, as ações de informar permitiram justificar a introdução de mais resoluções na partilha. Este é um aspeto que Ana valoriza na sua prática de condução de discussões. É notória a sua preocupação em justificar a ordem pela qual 
chama os alunos a apresentar os seus contributos e a justificar a introdução de certas resoluções na discussão.

Tal como no estudo de Ponte e Quaresma (2016), as ações de desafiar da professora na fase de comparação e avaliação de resoluções revelaram-se fundamentais, na medida em que permitiram aos alunos avançar na sua resposta face a uma expressão que tinham de interpretar e justificar. Estas ações desempenham também um papel importante na transição deste momento da discussão para o seguinte (conclusão), na justa medida em que as usa para levar os alunos a sintetizar os contributos mais importantes numa justificação. Para fomentar a conclusão da discussão socorre-se, ainda, de ações de apoiar e de informar para repetir argumentos e completar ideias que contribuam para melhorar a sistematização feita e para alertar para a prioridade das operações na resolução de uma expressão algébrica.

Ana gere o discurso com vista à promoção da comunicação matemática, incentivando os alunos a interpelar, argumentar e explicar raciocínios desenvolvidos. Esta forma de condução do discurso revela muito sobre a forma como encara o seu papel e o dos alunos na discussão, já que redireciona para a turma grande parte das questões que lhe são colocadas e assume a estratégia de convidar um aluno diferente do que está a transcrever a sua resolução no quadro, mas que recorreu à mesma estratégia, para tentar explicar o raciocínio seguido. Durante a condução da discussão, a professora apoia-se, essencialmente, no seu conhecimento da prática letiva em articulação com o da Matemática e da aprendizagem e dos alunos.

Este estudo mostra como a análise de estratégias de resolução de uma tarefa pode ser fundamental para o sucesso de uma discussão coletiva, ao permitir aos alunos avançar sobre as suas ideias iniciais, desbloqueando situações de impasse. Evidencia, ainda, tal como também sugere o estudo de Cengiz, Kline e Grant (2011), que a combinação das diversas ações de ensino empreendidas pela professora - mais que o seu uso isolado - são fundamentais para o sucesso da discussão.

\section{Referências}

BALL, D. L.; THAMES, M. H.; PHELPS, G. Content knowledge for teaching: what makes it special? Journal of Teacher Education, Washington, v. 59, n.5, p. 389 - 407, 2008.

BARDIN, L. Análise de conteúdo. Lisboa: Edições 70, 1994.

BOGDAN, R., \& BIKLEN, S. Investigação qualitativa em educação: uma introdução à teoria e aos métodos. Porto: Porto Editora, 1994. 
CENGIZ, N., KLINE, K., \& GRANT, T.J. Extending students' mathematical thinking during whole-group discussions. Journal of Mathematics Teacher Education, Dordrecht, n. 14, p.355374, 2011.

PONTE, J.P. Estudiando el conocimiento y el desarrollo profesional del profesorado de matemáticas. In N. PLANAS (Ed.), Educación matemática: teoría, crítica y prática, p.83-98, Barcelona: Graó, 2012.

PONTE, J.P. \& QUARESMA, M. Teachers' professional practice conducting mathematical discussions. Educational Studies in Mathematics, Dordrecht, n. 93, p.51-66, 2016.

PONTE, J.P., QUARESMA, M., \& MATA-PEREIRA, J. The challenge of mathematical discussions in teacher's professional practice. Didacticae, Barcelona, n. 1, p.45-59, 2017.

SHERIN, M. G. A balancing act: developing a discourse community in a mathematics classroom.

Journal of Mathematics Teacher Education, Dordrecht, n. 5, p.205-233, 2002.

SHULMAN, L. S. Knowledge and teaching: foundations of the new reform. Harvard Educational Review, Cambridge, v. 57, n. 1, p. 1-22, 1987.

SHULMAN, L. S. Those who understand: knowledge growth in teaching. Educational Researcher, Washington, v. 5, n. 2, p. 4-14, 1986.

STEIN, M.K., ENGLE, R.A., SMITH, M. S., \& HUGHES, E.K. Orchestrating productive mathematical discussions: five practices for helping teachers move beyond show and tell. Mathematical Thinking and Learning, Abingdon, n. 10, p.313-340, 2008.

Submetido em maio de 2018 Aprovado em agosto de 2018 